\title{
Is analogical reasoning just another measure of executive functioning?
}

\section{Lindsey Engle Richland $^{1 *}$ and Robert G. Morrison ${ }^{2}$}

1 Department of Education, University of California, Irvine, CA, USA

2 Department of Psychology, Loyola University Chicago, Chicago, IL, USA

*Correspondence: I.e.richland@uci.edu

\section{A commentary on}

Deficits in analogical reasoning in adolescents with traumatic brain injury.

by Krawczyk, D. C., Hanten, G., Wilde, E. A., Li, X., Schnelle, K. P., Merkley, T. L., Vasquez, A. C., Cook, L. G., McClelland, M., Chapman, S. B., and Levin, H. S. (2010). Front. Hum. Neurosci.4:62. doi: 10.3389/ fnhum.2010.00062

The present paper by Krawczyk et al. (2010) adds to a growing list of studies that have shown analogical reasoning to be critically dependent on what is known as executive functioning in the neuropsychological literature, and working memory in the cognitive (neuro)science literature. Specifically, analogy requires the maintenance, manipulation, and selective activation (or inhibition) of mental representations to identify, map correspondences, and draw inferences about higher-order similarity relationships (e.g., Waltz et al., 2000; Morrison et al., 2004; Bunge et al., 2005, 2009; Morrison, 2005; Green et al., 2006; Cho et al., 2007, 2010; Krawczyk et al., 2008; Morrison and Cho, 2008). Consistent with this, populations with limited executive functioning resources have shown reduced analogy performance when required to integrate multiple relations and/or inhibit featural distractors in favor of relational similarity (e.g., TBI adolescents: Krawczyk et al., 2010; children: Richland et al., 2006, 2010; Wright et al., 2008; Thibaut et al., 2010; older adults: Viskontas et al., 2004; and brain damaged adults: Morrison et al., 2004; Krawczyk et al., 2008). So is analogical reasoning simply another measure of executive function?

Analogy is pervasive in everyday learning and discovery. Importantly it allows us to make sense of and make inferences about new situations and information with respect to things we already know and understand (Holyoak and Thagard, 1995; Dunbar and Blanchette, 2001). Thus, theories of the development of analogy in children have frequently focused on relational knowledge as a necessary precondition for analogy (Rattermann and Gentner, 1998; Goswami, 2001). The importance of relational knowledge may also be seen in patients with damage to the temporal lobe. Morrison et al. (2004) and Krawczyk et al. (2008) and colleagues have previously found that patients with broad damage to anterior temporal lobe, an area associated with semantic knowledge, have difficulty with both verbal and visual analogies in spite of having preserved executive functions; however, the patterns of deficit are different than those of patients with damage to prefrontal cortex and their associated executive dysfunction. These findings are consistent with the current paper's finding that cortical differences in both prefrontal and temporal regions were associated with lower analogy performance.

We have recently begun to explore how executive functions and relational knowledge, and their underlying brain networks, may work together in the service of analogy. In one study, Richland et al. (2010), we exploited cross-cultural differences in relational knowledge and discovered a dissociation between the ability to inhibit featural distractors and integrate relations in analogy, two functions associated with executive functions which have traditionally correlated in studies of analogy (see Cho et al., 2010 for an exception using neuroimaging). Using a computational model of analogy we offered an explanation of the results, suggesting that more advanced relational knowledge structures reduce the demands for executive functions in analogy (Morrison et al., in press). Thus, prefrontal and temporal networks work together in analogy and the development or advanced functioning on one area affect demands on the other. In fact, we have also shown via modeling that the development of such advanced relational knowledge networks themselves may be dependent on executive functions (Doumas et al., 2010).

Thus, analogy is not simply another measure of executive functions, rather it is a whole brain activity, that is a profound test of our ability to think in everyday life, and as such is an excellent measure to evaluate the impact of traumatic brain injury on patients' ability to function.

\section{REFERENCES}

Bunge, S. A., Wendelken, C., Badre, D., and Wagner, A. D. (2005). Analogical reasoning and prefrontal cortex: evidence for separable retrieval and integration mechanisms. Cereb. Cortex 15, 239-249.

Bunge, S. A., Wendelken, C., and Helskog, E. H. (2009). Left, but not right, rostrolateral prefrontal cortex meets a stringent test of the relational integration hypothesis. Neuroimage 46, 338-342.

Cho, S., Holyoak, K. J., and Cannon, T. D. (2007). Analogical reasoning in working memory: resources shared among relational integration, interference resolution, and maintenance. Mem. Cognit. 35, 1445-1455.

Cho, S., Moody, T. D., Fernandino, L., Mumford, J. A., Poldrack, R. A., Cannon, T. D., Knowlton, B. J., and Holyoak, K. J. (2010). Common and dissociable prefrontal loci associated with component mechanisms of analogical reasoning. Cereb. Cortex 20, 524-533.

Dunbar, K., and Blanchette, I. (2001). The in vivo/in vitro approach to cognition: the case of analogy. Trends Cogn. Sci. 5, 335-339.

Doumas, L. A. A., Morrison, R. G., \& Richland, L. E. (2010). "Differences in development of analogy across cultures: a computational account," in Proceedings of the 32nd Annual Conference of the Cognitive Science Society, Portland, Oregon.

Goswami, U. (2001). "Analogical reasoning in children," in The Analogical mind: Perspectives from Cognitive Science, eds. D. Gentner, K. J. Holyoak, and B. N. Kokinov (Cambridge, MA: MIT Press), 437-470.

Green, A. E., Fugelsang, J. A., Kraemer, D. J. M., Shamosh, N. A., and Dunbar, K. N. (2006). Frontopolar cortex mediates abstract integration in analogy. Brain Res. 1096, 125-137.

Holyoak, K. J., and Thagard, P. (1995). Mental Leaps: Analogy in Creative Thought. Cambridge, MA: The MIT Press.

Krawczyk, D. C., Hanten, G., Wilde, E. A., Li, X., Schnelle, K. P., Merkley, T. L., Vasquez, A. C., Cook, L. G., 
McClelland, M., Chapman, S. B., and Levin, H. S. (2010). Deficits in analogical reasoning in adolescents with traumatic brain injury. Front. Hum. Neurosci. 4:62. doi: 10.3389/fnhum.2010.00062.

Krawczyk, D. C., Morrison, R. G., Viskontas, I., Holyoak, K. J., Chow, T. W., Mendez, M., Miller, B. L., and Knowlton, B. J. (2008). Distraction during relational reasoning: the role of prefrontal cortex in interference control. Neuropsychologia 46, 2020-2032.

Morrison, R. G. (2005). “Thinking in working memory," in Cambridge Handbook of Thinking and Reasoning, eds K. J. Holyoak and R. G. Morrison (New York, NY: Cambridge University Press), 457-473.

Morrison, R. G., and Cho, S. (2008). Neurocognitive process constraints on analogy: what changes to allow children to reason like adults? Behav. Brain Sci. 31, 391-392.

Morrison, R. G., and Doumas, L. A. A., and Richland, L. E. (in press). A computational account of children's analogical reasoning: balancing inhibitory control in working memory and relational representation. Dev. Sci.
Morrison, R. G., Krawczyk, D., Holyoak, K. J., Hummel, J. E., Chow, T., Miller, B., and Knowlton, B. J. (2004). A neurocomputational model of analogical reasoning and its breakdown in frontotemporal lobar degeneration. J. Cogn. Neurosci. 16, 260-271.

Rattermann, M. J., and Gentner, D. (1998). More evidence for a relational shift in the development of analogy: children's performance on a causal-mapping task. Cogn. Dev. 13, 453-478.

Richland, L. E., Chan, T.-K., Morrison, R. G., and Au, T. K.-F. (2010). Young children's analogical reasoning across cultures: similarities and differences. J. Exp. Child. Psychol. 105, 146-153.

Richland, L. E., Morrison, R. G., and Holyoak, K. J. (2006). Children's development of analogical reasoning: insights from scene analogy problems. J. Exp. Child. Psychol. 94, 249-273.

Thibaut, J., French, R., and Vezneva, M. (2010). The development of analogy making in children: cognitive load and executive functions. J. Exp. Child. Psychol. $106,1-19$.

Viskontas, I. V., Morrison, R. G., Holyoak, K. J., Hummel, J. E., and Knowlton, B. J. (2004). Relational integra- tion, inhibition and analogical reasoning in older adults. Psychol. Aging 19, 581-591.

Waltz, J. A., Lau, A., Grewal, S. K., and Holyoak, K. J. (2000). The role of working memory in analogical mapping. Memory and Cognition 28, 1205-1212.

Wright, S. B., Matlen, B. J., Baym, C. L., Ferrer, E., and Bunge, S. A. (2008). Neural correlates of fluid reasoning in children and adults. Front. Hum. Neurosci. 1:8. doi: 10.3389/neuro.09/008.2007.

Received: 29 August 2010; accepted: 31 August 2010; published online: 20 September 2010.

Citation: Richland LE and Morrison RG (2010) Is analogical reasoning just another measure of executive functioning? Front. Hum. Neurosci. 4:180. doi: 10.3389/ fnhum.2010.00180

Copyright (c) 2010 Richland and Morrison. This is an open-access article subject to an exclusive license agreement between the authors and the Frontiers Research Foundation, which permits unrestricted use, distribution, and reproduction in any medium, provided the original authors and source are credited. 